11

\title{
Мартенситное превращение, магнитотранспортные свойства и магнитокалорический эффект в сплаве $\mathrm{Ni}_{47} \mathrm{Mn}_{42} \mathrm{In}_{11}$
}

\author{
(C) Ю.В. Калетина ${ }^{1}$, Е.Г. Герасимов ${ }^{1,2}$, П.Б. Терентьев ${ }^{1,2}$, А.Ю. Калетин ${ }^{1,2}$ \\ ${ }^{1}$ Институт фризики металлов им. М.Н. Михеева УрО РАН, \\ Екатеринбург, Россия \\ ${ }^{2}$ Уральский федеральный университет им. первого Президента России Б.Н. Ельцина, \\ Екатеринбург, Россия \\ E-mail: kaletina@imp.uran.ru
}

(Поступила в Редакцию 14 июня 2018 г.

В окончательной редакции 8 ноября 2018 г.

Принята к публикации 8 ноября 2018 г.)

Исследованы структура, электрические свойства и магнитокалорический эффект в ферромагнитном сплаве $\mathrm{Ni}_{47} \mathrm{Mn}_{42} \mathrm{In}_{11}$, в котором температура мартенситного превращения близка к комнатной температуре и практически совпадает с температурой Кюри аустенита. Обнаружено, что спонтанное превращение из мартенсита в аустенит сопровождается уменьшением удельного сопротивления на $45 \%$. При индуцированном магнитным полем мартенситном превращении наблюдается отрицательное магнитосопротивление, достигающее $\approx 15 \%$ в магнитном поле с напряженностью 18 кОе. С использованием уравнения Клапейрона-Клаузиуса вычислена температурная зависимость максимального изменения энтропии при индуцированном магнитным полем мартенситном превращении. Показано, что максимальные значения магнитосопротивления и магнитокалорического эффекта наблюдаются вблизи температуры спонтанного мартенситного превращения.

Работа выполнена в рамках государственного задания ФАНО России (темы „Структура“, номер гос. регистрации АААА-А18-118020190116-6 и „Магнит“, номер гос. регистрации АААА-А18-118020290129-5) при частичной поддержке РФФИ (проект № 16-03-00043).

DOI: 10.21883/FTT.2019.04.47428.166

\section{1. Введение}

В отличие от традиционных парамагнитных сплавов с памятью формы (Ti-Ni и др.), в ферромагнитных сплавах с памятью формы $\left(\mathrm{Ni}_{2} \mathrm{MnGa}\right.$, нестехиометрические сплавы на основе Ni-Mn-In, Ni-Mn-Sn, Ni-Mn-Sb) мартенситное превращение можно контролировать не только при изменении температуры, но и при изменении внешнего магнитного поля. Ферромагнитные сплавы Гейслера с мартенситным превращением представляют особый класс материалов, в которых существуют магнитоуправляемый эффект памяти формы, гигантские магнитострикция, магнитосопротивление, магнитокалорический эффект и другие свойства и эффекты [1-13]. Для ферромагнитных сплавов Гейслера важно сочетание трех основных факторов. Во-первых, должна существовать сильная зависимость температуры мартенситного превращения $T_{\mathrm{M}}$ от напряженности внешнего магнитного поля. Во-вторых, структура, электросопротивление, намагниченность и другие свойства сплавов в мартенситном и аустенитном структурных состояниях должны существенно различаться. И, в-третьих, мартенситное превращение должно происходить вблизи комнатной температуры. Сочетание первых двух факторов приводит к тому, что даже небольшое внешнее магнитное поле может сильно изменять физические свойства сплавов, вызывая в них мартенситное превращение. Третий фактор определяет степень и возможность их практического использования.
В сравнительно недавно обнаруженных новых нестехиометрических ферромагнитных сплавах Гейслера на основе Ni-Mn-In реализуются все три основных фактоpa [2,4,5-13]. Ранее нами были исследованы закономерности концентрационного и индуцированного внешним магнитным полем изменения температуры мартенситного перехода, влияние фазового состава на структуру сплавов $\mathrm{Ni}_{47-x} \mathrm{Mn}_{42+x} \operatorname{In}_{11}(x=0,1,2)$ [14-17]. В высокотемпературном состоянии сплавы находятся в аустенитном состоянии с упорядоченной кубической решеткой типа $L 2_{1}$. При охлаждении наблюдается мартенситное превращение, температура которого понижается при уменьшении соотношения $\mathrm{Ni} / \mathrm{Mn}$. При комнатной температуре в зависимости от состава сплава наблюдали либо двухфазную структуру, состоящую из упорядоченной $L 2_{1}$ фазы и мартенситных кристаллов, либо однофазную структуру $L 2_{1}$.

Целью настоящей работы являлось исследование электросопротивления, магнитосопротивления и магнитокалорического эффекта в тройном сплаве $\mathrm{Ni}_{47} \mathrm{Mn}_{42} \mathrm{In}_{11}$, в котором температура мартенситного превращения $T_{\mathrm{M}} \approx 325 \mathrm{~K}$ близка к комнатной температуре и практически совпадает с температурой Кюри аустенита $T_{\mathrm{CA}}$.

\section{2. Методика эксперимента}

Сплав $\mathrm{Ni}_{47} \mathrm{Mn}_{42} \mathrm{In}_{11}$ был выплавлен методом электродуговой плавки в атмосфере аргона. После плавки 


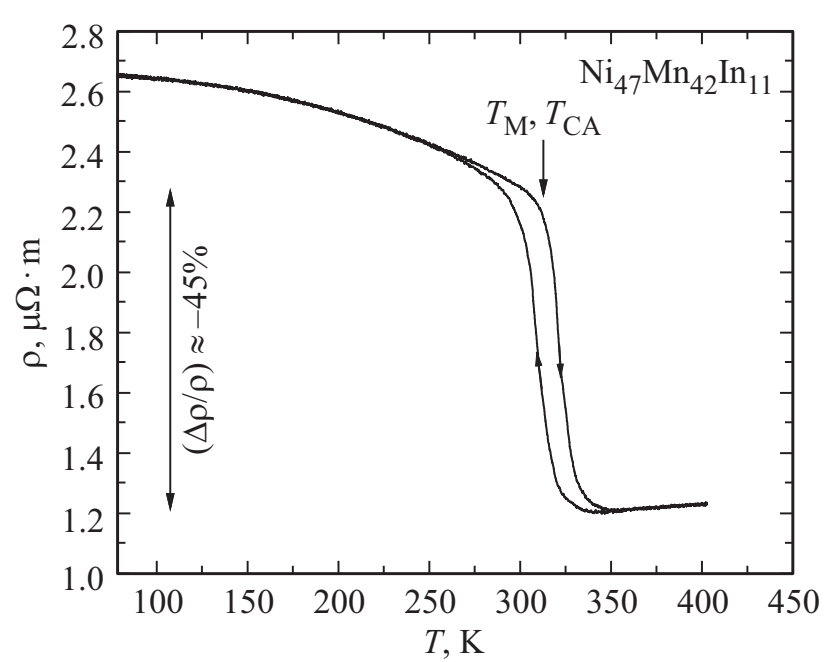

Рис. 1. Температурная зависимость удельного электросопротивления сплава $\mathrm{Ni}_{47} \mathrm{Mn}_{42} \operatorname{In}_{11}$.

слиток был подвергнут гомогенизирующему отжигу в вакууме в запаянной кварцевой ампуле при температуpe $1123 \mathrm{~K}$ в течение $24 \mathrm{~h}$ с последующим охлаждением на воздухе.

Исследования структуры и магнитных свойств проводили в ЦКП Испытательный центр нанотехнологий и перспективных материалов ИФМ УрО РАН.

Структурные исследования выполнены на оптическом микроскопе „Neophot-30“ на шлифах после травления. Электронно-микроскопические исследования выполняли на просвечивающем электронном микроскопе JEM-200СХ и сканирующем электронном микроскопе „Quanta-200“ с локальным микрорентгеноспектральным анализом.

Магнитные измерения выполнены с использованием импульсного вибромагнитометра в магнитных полях с напряженностью до $350 \mathrm{kOe}$, удельное электросопротивление измеряли четырехконтактным методом в магнит- ном поле с напряженностью до $18 \mathrm{kOe}$ в диапазоне температур 80-400 K.

\section{3. Результаты исследования и обсуждение}

На рис. 1 приведены температурные зависимости удельного электросопротивления $\rho(T)$ сплава $\mathrm{Ni}_{47} \mathrm{Mn}_{42} \mathrm{In}_{11}$, измеренные при нагреве и охлаждении. При нагреве сплава от $80 \mathrm{~K}$ до температуры обратного мартенситного превращения $T_{\mathrm{M}} \approx 325 \mathrm{~K}$ зависимость $\rho(T)$ имеет неметаллический характер. С ростом температуры наблюдается, хоть и небольшое, но уменьшение удельного электросопротивления от 2.65 до $2.3 \mu \mathrm{Ohm} \cdot \mathrm{m}$. При дальнейшем нагреве, в области температуры $T_{\mathrm{M}}$, наблюдается резкий скачок электросопротивления с 2.4 до $1.2 \mu \mathrm{Ohm} \cdot \mathrm{m}$. Он связан с изменением структуры сплава от мартенситной при $T<T_{\mathrm{M}}$ к аустенитной при $T>T_{\mathrm{M}}$. Далее, при нагреве выше $T_{\mathrm{M}}$, электросопротивление увеличивается с ростом температуры, то есть зависимость $\rho(T)$ имеет нормальный металлический характер. Как и мартенситное превращение, зависимость $\rho(T)$ характеризуется существованием температурного гистерезиса. Максимальное относительное изменение удельного электросопротивления $\Delta \rho / \rho$ при спонтанном мартенситном превращении составляет 45\%. Таким образом, изменение типа кристаллической решетки в ходе мартенситного превращения сопровождается существенным изменением сопротивления. Неметаллический характер зависимости $\rho(T)$ при $T<T_{\mathrm{M}}$ может быть обусловлен тем, что небольшое количество областей с аустенитной структурой, имеющей более низкие значения удельного электросопротивления, начинает образовываться в сплаве уже при температурах значительно более низких, чем $T_{\mathrm{M}}$.

Структурные исследования согласуются с температурной зависимостью удельного электросопротивления. В сплаве $\mathrm{Ni}_{47} \mathrm{Mn}_{42} \mathrm{In}_{11}$ температура Кюри аустенита a

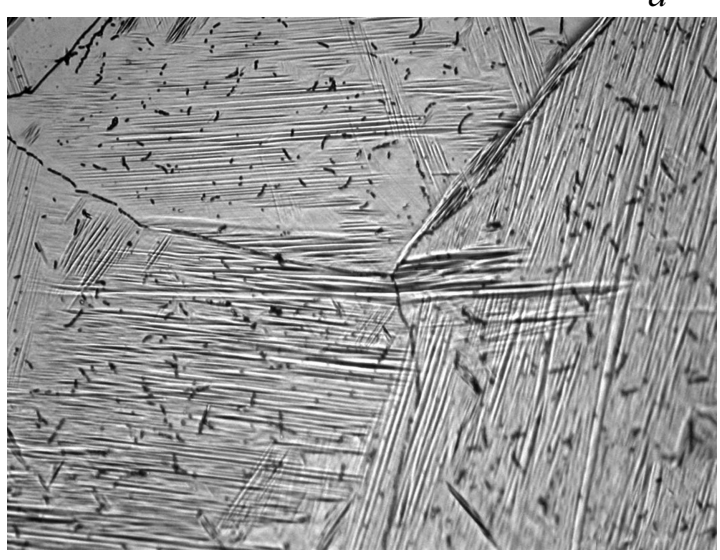

$80 \mu \mathrm{m}$

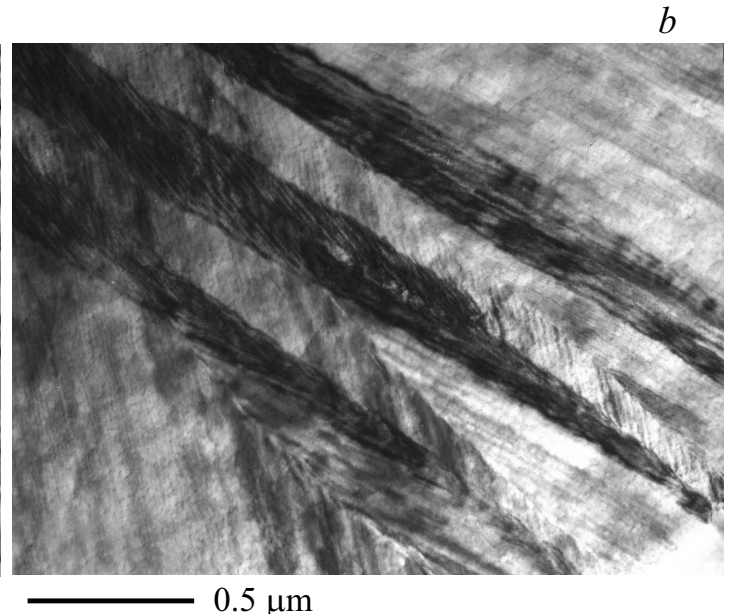

$0.5 \mu \mathrm{m}$

Рис. 2. Микроструктура сплава $\mathrm{Ni}_{47} \mathrm{Mn}_{42} \mathrm{In}_{11}$ после отжига. 


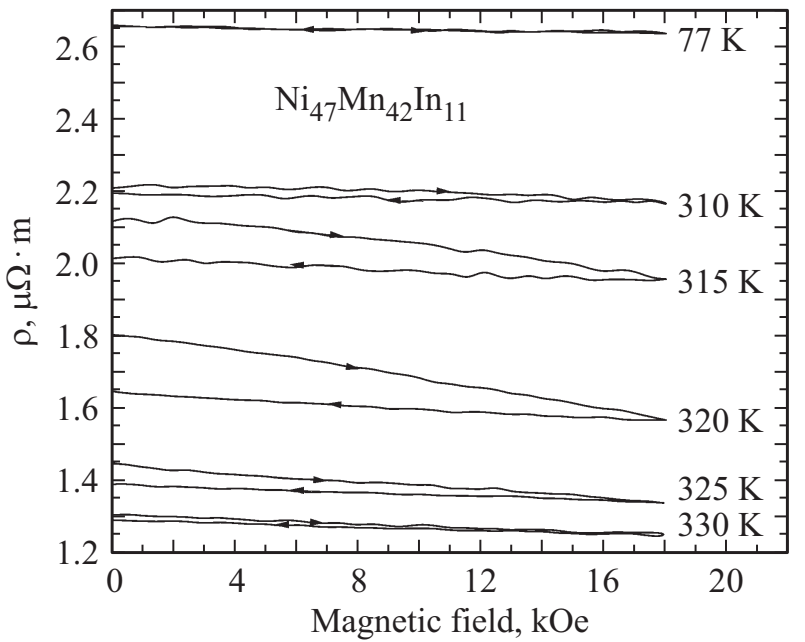

Рис. 3. Зависимости удельного электросопротивления исследованного сплава $\mathrm{Ni}_{47} \mathrm{Mn}_{42} \mathrm{In}_{11}$ от напряженности магнитного поля при различных температурах.

близка к температуре мартенситной точки $T_{\mathrm{CA}} \approx T_{\mathrm{M}}$. Поэтому можно говорить о так называемом магнитоструктурном фазовом переходе. При комнатной температуре в исходном состоянии структура сплава $\mathrm{Ni}_{47} \mathrm{Mn}_{42} \mathrm{In}_{11}$ двухфазная, состоящая из $L 2_{1}$ фазы и мартенсита (рис. 2). При металлографическом исследовании при комнатной температуре на поверхности шлифов отчетливо виден мартенситный рельеф. В структуре наряду с высокотемпературной фазой $L 2_{1}$ хорошо выявляются кристаллы мартенсита. Они располагаются определенным образом, образуя сочленения подобные пакетам (см. рис. 2,a). Как правило, внутри пакетов тонкие мартенситные пластины с плоскими границами разделов располагаются параллельно друг другу. Внутри одного зерна в соседних пакетах кристаллы часто располагаются под углом $\sim 60 \mathrm{deg}$. Проведенные нами ранее $[15,16]$ кристаллографический и рентгеноструктурный анализы показали, что при охлаждении в сплаве $\mathrm{Ni}_{47} \mathrm{Mn}_{42} \mathrm{In}_{11}$ мартенситное превращение идет по типу $L 2_{1} \rightarrow 14 M$ с образованием модулированной структуры мартенсита (см. рис. $2, b$ ). Мартенсит в сплаве $\mathrm{Ni}_{47} \mathrm{Mn}_{42} \mathrm{In}_{11}$ имеет моноклинную решетку. Внутри мартенситных кристаллов наблюдаются дефекты упаковки.

На рис. 3 показаны зависимости удельного электросопротивления сплава $\mathrm{Ni}_{47} \mathrm{Mn}_{42} \mathrm{In}_{11}$ от напряженности внешнего магнитного поля $\rho(H)$ при разных температурах. Измерения $\rho(H)$ при каждой температуре проводились после предварительного охлаждения образца до $78 \mathrm{~K}$, чтобы начальное структурное состояние образца было всегда одинаковым. При всех температурах наблюдается отрицательное магнитосопротивление. Вблизи температуры $T_{\mathrm{M}} \approx 325 \mathrm{~K}$ изменение электросопротивления с ростом магнитного поля значительно увеличивается и зависимости $\rho(H)$ характеризуются наличием гистерезиса. Наличие гистерезиса на зависимостях $\rho(H)$ указывает на то, что вблизи $T_{\mathrm{M}}$ происходит необра- тимое индуцированное магнитным полем мартенситное превращение.

На рис. 4 представлена температурная зависимость магнитосопротивления исследуемого сплава в магнитном поле $18 \mathrm{kOe}(\rho(H=18 \mathrm{kOe})-\rho(H=0)) / \rho(H=0)$. Резкий рост магнитосопротивления наблюдается в узкой области температур вблизи температуры $T_{\mathrm{M}}$, где происходит индуцируемое магнитным полем мартенситное превращение. Максимальная абсолютная величина магнитосопротивления достигает $\approx 15 \%$ и оказывается значительно ниже, чем изменение сопротивления при спонтанном мартенситном превращении, которое составляет $\approx 45 \%$ (см. рис. 1 ). Низкие значения магни-

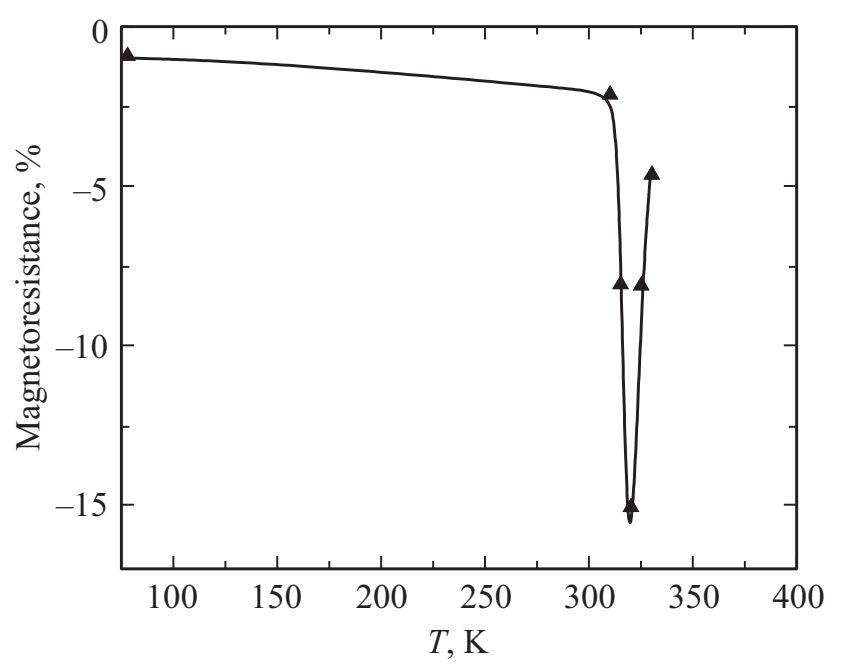

Рис. 4. Температурная зависимость магнитосопротивления сплава $\mathrm{Ni}_{47} \mathrm{Mn}_{42} \mathrm{In}_{11}$ в магнитном поле 18 кОе.

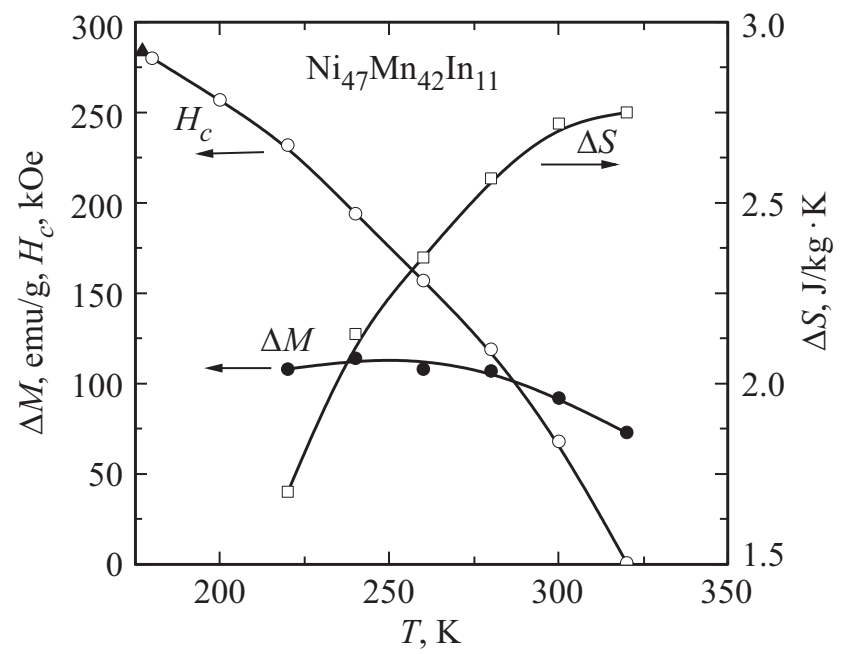

Рис. 5. Температурные зависимости критического поля $H_{\mathrm{c}}$, в котором начинается мартенситное превращение, изменения намагниченности сплава $\Delta M$ при индуцированном магнитным полем мартенситном превращении и вычисленного с использованием уравнения Клапейрона-Клаузиуса изменения энтропии $\Delta S$ при мартенситном превращении для сплава $\mathrm{Ni}_{47} \mathrm{Mn}_{42} \mathrm{In}_{11}$. 
тосопротивления в магнитном поле $18 \mathrm{kOe}$ обусловлены тем, что напряженности магнитного поля $18 \mathrm{kOe}$ недостаточно, чтобы весь образец переходил в аустенитное состояние, поскольку индуцируемое магнитным полем мартенситное превращение происходит в широком интервале магнитных полей, достигающем $200 \mathrm{kOe}$ [14].

На рис. 5 показаны температурные зависимости критического поля мартенситного превращения $H_{\mathrm{c}}(T)$ в сплаве и разности $\Delta M(T)$ между намагниченностями индуцированном магнитным полем аустенитном состоянии и исходным мартенситном состоянии, определенные нами ранее в работе [17]. Характерной особенностью зависимости $H_{\mathrm{c}}(T)$ является резкий рост значений критического поля по мере удаления от температуры мартенситного превращения, при этом намагниченность в индуцированном магнитным полем аустените слабо изменяется с изменением температуры. Индуцированное магнитным полем мартенситное превращение является фазовым переходом первого рода, поэтому можно вычислить максимальное изменение магнитной части энтропии $\Delta S$ или магнитокалорический эффект, используя широко известное уравнение КлапейронаКлаузиуса [18,19]

$$
\Delta S(T)=-\left(d H_{\mathrm{c}}(T) / d T\right) \Delta M(T),
$$

где $d H_{\mathrm{c}}(T) / d T-$ скорость изменения критического поля $H_{\mathrm{c}}$ с изменением температуры; $\Delta M(T)=$ $=\left(M_{\mathrm{a}}-M_{\mathrm{m}}\right)-$ разница в намагниченности сплава в аустенитном состоянии $M_{\text {a }}$ и индуцированном магнитным полем мартенситном состоянии $M_{\mathrm{m}}$. Вычисленная с использованием уравнения (1) зависимость $\Delta S(T)$ приведена на рис. 5. Изменение энтропии в области индуцируемого магнитным полем магнитоструктурного фазового перехода положительное, что характерно для нестехиометрических сплавов Гейслера на основе Ni-Mn-In, Ni-Mn-Sn [4,8,9,11,12]. Максимальное изменение энтропии $\Delta S \approx 2.75 \mathrm{~J} / \mathrm{kg} \cdot \mathrm{K}$ достигается при температуре близкой к $T_{\mathrm{CA}} \approx 325 \mathrm{~K}$, поскольку вблизи этой температуры наблюдаются максимальные значения $d H_{\mathrm{c}}(T) / d T$.

\section{4. Заключение}

Исследованы структура, электросопротивление, магнитосопротивление и магнитокалорический эффект в ферромагнитном сплаве $\mathrm{Ni}_{47} \mathrm{Mn}_{42} \mathrm{In}_{11}$.

Измерения температурных зависимостей электросопротивления показали, что относительное изменение электросопротивления в ходе спонтанного мартенситного превращения составляет $45 \%$.

Установлено, что отрицательное магнитосопротивление и максимальный магнитокалорический эффект наблюдаются вблизи температур мартенситного превращения и магнитного перехода $T_{\mathrm{CM}} \approx T_{\mathrm{C}} \approx 325 \mathrm{~K}$.

Исследуемый сплав $\mathrm{Ni}_{47} \mathrm{Mn}_{42} \mathrm{In}_{11}$, обладая большим магнитосопротивлением, может быть использован как многофункциональный материал для практического применения.

\section{Список литературы}

[1] А.Н. Васильев, В.Д. Бучельников, Т. Такаги, В.В. Ховайло, Э.И. Эстрин. УФН 173, 577 (2003).

[2] Y. Sutou, Y. Imano, N. Koeda, T. Omori, R. Kainuma, K. Ishida, K. Oikawa. Appl. Phys. Lett. 85, 4358 (2004).

[3] В.Д. Бучельников, А.Н. Васильев, В.В. Коледов, В.В. Ховайло, С.В. Таскаев, В.Г. Шавров. УФН 176, 900 (2006).

[4] V.D. Buchelnikov, V.V. Sokolovskiy. Phys. Met. Metallography 112, 633 (2011).

[5] K. Koyama, H. Okada, K. Watanabe, T. Kanomata, R. Kainuma, W. Ito, K. Oikawa, K. Ishida. Appl. Phys. Lett. 89, 182510 (2006).

[6] S.Y. Yu, Z.H. Liu, G.D. Liu, J.L. Chen, Z.X. Cao, G.H. Wu, B. Zhang, X.X. Zhang. Appl. Phys. Lett. 89, 162503 (2006).

[7] S. Chatterjee, S. Majumdar, V. Koledov. AIP Conf. Proc. 1447, 1161 (2012).

[8] V.K. Sharma, M.K. Chattopadhyay, L.S. Sharath Chandra, Ashish Khandelwal, R.K. Meena, S.B. Roy. Eur. Phys. J. Appl. Phys. 62, 30601 (2013).

[9] Y. Liu, C. Jing, X. He, Y. Zhang, K. Xu, Z. Li. Phys. Status Solidi A 214, 6, 1600906 (2017).

[10] X. Chen, V.B. Naik, R. Mahendiran, R.V. Ramanujan. J. Alloy. Compd. 618, 187 (2016).

[11] N.H. Dan, N.H. Duc, N.H. Yen, P.T. Thanh, L.V. Bau, N.A. Bang, N.T. Mai, P.K. Anh, T.D. Thanh, T.L. Phan. J. Magn. Magn. Mater. 374, 372 (2015).

[12] A. Quetz, Y. Koshkidko, I. Titov, I. Rodionov, S. Pandey, A. Aryal, P.J. Ibarra-Gaytan, V. Prudnikov, A. Granovsky, I. Dubenko. J. Alloy. Compd. 683, 139 (2016).

[13] S. Pandey, A. Quetz, A. Aryal, T. Samanta, I. Dubenko, S. Stadler, N. Ali. AIP Adv. 6, 056213 (2016).

[14] Ю.В. Калетина, Е.Г. Герасимов. ФТТ 56, 1583 (2014).

[15] Ю.В. Калетина, Н.Ю. Фролова, В.М. Гундырев, А.Ю. Калетин. ФТТ 58, 1606 (2016).

[16] Ю.В. Калетина, И.Г. Кабанова, Н.Ю. Фролова, В.М. Гундырев, А.Ю. Калетин. ФТТ 59, 1984 (2017).

[17] Ю.В. Калетина, Е.Г. Герасимов, В.М. Счастливцев, Е.А. Фокина, П.Б. Терентьев. ФММ 114, 911 (2013).

[18] M. Balli, O. Sari, D. Fruchart, J. Forchelet. EPJ Web Conf. 29, 00005 (2012).

[19] N.V. Mushnikov, E.G. Gerasimov, P.B. Terentev, V.S. Gaviko, K.A. Yazovskikh, A.M. Aliev. J. Magn. Magn. Mater. 440, 89 (2017).

Редактор Д.В. Жуманов 